\title{
Effects of dietary sulphur sources on concentrations of hydrogen sulphide in the rumen head-space gas of dairy cows
}

\author{
R.J. Dewhurst ${ }^{1 \dagger}$, E.J. Kim ${ }^{1}$, R.T. Evans ${ }^{1}$, A.R.J. Cabrita ${ }^{2}$ and A.J.M. Fonseca ${ }^{2}$ \\ ${ }^{1}$ Institute of Grassland and Environmental Research, Plas Gogerddan, Aberystwyth SY23 3EB, UK; ${ }^{2}$ Universidade do Porto, Rua Padre Armando Quintas, 4485-661, \\ Vairão VC, Portugal
}

(Received 15 September 2006; Accepted 27 November 2006)

Three change-over design experiments investigated the origin of hydrogen sulphide in the rumen head-space gas of dairy cows, comparing the effects of single iso-S additions of methionine, cysteine and sodium sulphate, as well as the effects of single meals of fresh ryegrass or white clover. The concentration of hydrogen sulphide in rumen gas declined close to zero within $4 \mathrm{~h}$ after withdrawal of the previous feed. Sulphur sources were then given to cows and concentrations of hydrogen sulphide recorded in rumen head-space gas at 30-min intervals. Cysteine addition (8g) led to a rapid (within $30 \mathrm{~min}$ ) and a large (490 and 957 p.p.m. respectively in two experiments) increase in hydrogen sulphide concentration. Concentrations were significantly less following methionine addition. Increasing levels of cysteine addition led to significant increases in hydrogen sulphide concentrations ( $\mathrm{P}<0.001$ for the linear effect), although peak hydrogen sulphide was delayed and concentrations remained higher for longer with the highest $(12 \mathrm{~g})$ addition of cysteine $(\mathrm{P}<0.01$ for the 'cysteine level' $\times$ 'time' interaction). The increase in concentration of hydrogen sulphide from sodium sulphate was smaller (230 p.p.m.) and slower (2 h) than for cysteine. Despite the much higher intake of cystine for white clover in comparison with perennial ryegrass $(\mathrm{P}<0.001)$, there was almost no increase in hydrogen sulphide concentration in rumen head-space gas from cows fed white clover. It seems likely that this is associated with the use of sulphur to produce thiocyanate to detoxify the hydrogen cyanide from cyanogenic white clover.

Keywords: amino acids, hydrogen sulphide, rumen, ryegrass, white clover

\section{Introduction}

In earlier studies, high concentrations of sulphides, particularly hydrogen sulphide, were observed in the rumen headspace gas of dairy cows fed grass silage and concentrates (Dewhurst et al., 2001). Hydrogen sulphide is an extremely toxic gas and high concentrations lead to a range of neurological symptoms (polioencephalomalacia; Gould et al., 1997) and inappetance (Bird, 1972b). Earlier work in this area has looked either at concentrations of hydrogen sulphide in rumen liquor, with an emphasis on low-quality roughages (e.g. Bird and Hume, 1971), or at the very high concentrations of hydrogen sulphide in rumen gas when drinking water is contaminated with high levels of sulphate (Gould et al., 1997). It is not clear, however, to what extent the production of hydrogen sulphide from normal diets might be involved in the regulation of intake and performance.

\footnotetext{
${ }^{\dagger}$ Present address: Lincoln University, PO Box 84, Lincoln 7647, Canterbury, New Zealand. E-mail: dewhursr@lincoln.ac.nz
}

Our studies have focussed on hydrogen sulphide in rumen gas because there are several reasons why it may be more significant than hydrogen sulphide in the liquid phase in relation to effects in the animal. Pulmonary absorption of inhaled rumen gas represents a significant route for absorption of hydrogen sulphide (Dougherty et al., 1962) and one which bypasses detoxification in the liver (Gould et al., 1997). Further, Gould et al. (1997) found that variation in hydrogen sulphide in rumen gas was larger than changes in rumen liquor.

Most of the sulphur in herbage is contained in methionine and cystine within proteins (Havlin et al., 1999). Earlier studies showed higher production of hydrogen sulphide from cyst(e)ine than from iso-S quantities of methionine or inorganic sulphate (Bird, 1972a). The first objective of this work was to investigate whether these differences are also evident when looking at the concentration of hydrogen sulphide in rumen head-space gas. The second objective was to evaluate the concentrations of hydrogen sulphide from two of the major grazed forages in temperate agricultureperennial ryegrass (Lolium perenne) and white clover 
(Trifolium repens). This comparison was chosen because of the anticipated higher levels of protein (and $\mathrm{S}$ amino acids) in white clover as well as the higher rumen degradability of white clover protein (Broderick and Albrecht, 1997).

\section{Material and methods}

Animals and their management

This work was carried out under a UK Home Office Project License (Animals (Scientific Procedures) Act, 1986). The study used Holstein-Friesian dairy cows that had previously been prepared with rumen cannulae (Bar-Diamond, Parma, Idaho, USA).

On each measurement day, cows were fasted for about $4 \mathrm{~h}$ until concentrations of hydrogen sulphide in rumen gas declined close to zero. During this period cows had continual access to water. Cows were then given a range of feeds or feed components (see below) and concentrations of hydrogen sulphide were recorded for a further $2.5 \mathrm{~h}$. Cows for experiments 1 and 2 were housed and given ad libitum access to grass silage with concentrates at $2 \mathrm{~kg}$ per milking. Cows for experiment 3 were grazing perennial ryegrass and given $3 \mathrm{~kg}$ concentrates at each milking prior to measurements. Cows were housed for the measurements reported here. Chemical composition of the forage and concentrates offered prior to the measurements recorded here, are given in Tables 1 and 2. Chemical analyses were performed using the methods described by Dewhurst et al. (2000).

\section{Sampling and measuring rumen gas}

Duplicate samples of rumen gas were collected from each cow and concentrations of hydrogen sulphide recorded at $30,60,90,120$ and 150 min after feeds were given. Samples of rumen head-space gas (approx. 1l) were obtained using the procedures described by Dewhurst et al.

Table 1 Chemical composition of the grass silages (experiments 1 and 2) or perennial ryegrass (experiment 3) offered to cows prior to measurements made in these experiments

\begin{tabular}{lccc}
\hline \hline & \multicolumn{3}{c}{ Experiment } \\
\cline { 2 - 4 } & 1 & 2 & 3 \\
\hline Dry matter (DM; g/kg as-fed) & 200 & 222 & 187 \\
Organic matter (g/kg DM) & 914 & 901 & 925 \\
Neutral-detergent fibre (g/kg DM) & 572 & 429 & 501 \\
Acid-detergent fibre (g/kg DM) & 341 & 271 & 328 \\
Crude protein (g/kg DM) & 120 & 176 & 155 \\
Ether extract (g/kg DM) & 30.8 & 44.8 & 18.0 \\
Water-soluble carbohydrates (g/kg DM) & 44.3 & 58.7 & 188 \\
pH & 3.86 & 3.64 & - \\
Ammonia-nitrogen (g/kg DM) & 2.46 & 3.27 & - \\
Lactic acid (g/kg DM) & 86.6 & 90.3 & - \\
Acetic acid (g/kg DM) & 19.3 & 22.4 & - \\
Butyric acid (g/kg DM) & $\mathrm{ND}^{\dagger}$ & 0.6 & - \\
\hline \hline
\end{tabular}

${ }^{\dagger} \mathrm{ND}=$ not detected.
Table 2 Chemical composition of the concentrates offered to cows prior to measurements made in these experiments

\begin{tabular}{lccc}
\hline \hline & \multicolumn{3}{c}{ Experiment } \\
\cline { 2 - 4 } & 1 & 2 & 3 \\
\hline Dry matter (DM; g/kg as-fed) & 849 & 852 & 872 \\
Organic matter (g/kg DM) & 925 & 921 & 914 \\
Neutral-detergent fibre (g/kg DM) & 197 & 167 & 151 \\
Acid-detergent fibre (g/kg DM) & 94 & 105 & 82 \\
Crude protein (g/kg DM) & 208 & 240 & 227 \\
Acid hydrolysis ether extract (g/kg DM) & 49.8 & 55.5 & 25.0 \\
Water-soluble carbohydrates (g/kg DM) & 96.8 & 78.3 & 162 \\
Starch (g/kg DM) & 344 & 314 & 338 \\
\hline \hline
\end{tabular}

(2001). Concentrations of hydrogen sulphide were measured immediately using a Crowcon Triple Plus + meter (Crowcon Detection Instruments Ltd, Oxfordshire, UK), modified to read in the range 0 to 700 p.p.m. and calibrated using a standard obtained from Sigma-Aldrich Chemical Company (Poole, Dorset, UK). Samples with higher concentrations were diluted with carbon dioxide and reanalysed.

\section{Experiment 1}

This study evaluated effects of iso-sulphur additions of inorganic and organic sulphur sources to the rumen on hydrogen sulphide concentrations in rumen head-space gas. Four cows in late lactation were used in a $4 \times 4$ Latin-square design experiment with measurements separated by periods of 5 to 7 days. The four treatments were a control (no addition) and three iso-sulphur additions (all obtained from Fisher Scientific UK Ltd, Leicestershire, UK): $9.98 \mathrm{~g}$ sodium sulphate (in $100 \mathrm{ml}$ water), $8.52 \mathrm{~g} \mathrm{~L}$-cysteine (in $100 \mathrm{ml}$ water) or $9.32 \mathrm{~g} \mathrm{L-methionine} \mathrm{(as} \mathrm{a} \mathrm{dry} \mathrm{powder).}$ These additions were designed to provide about 0.05 of daily $S$ intake for these cows. Sulphur-containing compounds were added to the rumen at $1330 \mathrm{~h}$.

\section{Experiment 2}

This study evaluated effects of increasing levels of cysteine additions to the rumen on hydrogen sulphide concentrations in rumen head-space gas. Four cows (three in latelactation and one non-lactating) were used in a $4 \times 4$ Latin-square design experiment with measurements separated by periods of 2 to 5 days. The four treatments were $0,4,8$ and $12 \mathrm{~g}$ of L-cysteine dissolved in $100 \mathrm{ml}$ of water. Cysteine was added to the rumen between 1315 and $1345 \mathrm{~h}$ on different days and rumen head-space gas collected at 30-min intervals thereafter.

\section{Experiment 3}

This study evaluated effects of perennial ryegrass and white clover on hydrogen sulphide concentrations in rumen head-space gas. Four cows in early- to mid-lactation were used in a change-over design experiment with two periods and two treatments. Cows grazed perennial ryegrass in the 
field until $0730 \mathrm{~h}$, were then brought inside, given $3 \mathrm{~kg}$ of concentrates and milked at $0800 \mathrm{~h}$. Cows remained in stalls and no further feed was offered whilst hydrogen sulphide concentrations were monitored in rumen head-space gas until they were close to zero. Cows were offered $9.5 \mathrm{~kg}$ of their allotted herbage at $1350 \mathrm{~h}$. Perennial ryegrass (cv. Fennema) and white clover (cv. AberHerald) were taken from pure stands which had been fertilized $(31 \mathrm{~kg} / \mathrm{ha} \mathrm{N}$, $6.2 \mathrm{~kg} / \mathrm{ha} \mathrm{P}_{2} \mathrm{O}_{5}$ and $6.2 \mathrm{~kg} / \mathrm{ha} \mathrm{K}_{2} \mathrm{O}$ ) and regrown for 38 days prior to the experiment, which ran on 8 and 10 July 2002. Herbage was cut using hand shears and transported from the field immediately prior to being offered to cows. Cows had generally consumed their herbage allocation by $1410 \mathrm{~h}$, in each period one cow refused small amounts of white clover (2.1 and $0.8 \mathrm{~kg}$ respectively), which was mechanically chopped and given via the rumen cannula at $1420 \mathrm{~h}$. Recording of hydrogen sulphide concentrations in rumen head-space gas commenced at $1430 \mathrm{~h}$.

Herbage samples were taken each day and analysed according to Dewhurst et al. (2000). Amino acids were analysed using a Biochrom 20 amino acid analyser (Biochrom Ltd, Cambridge, UK). This fully automated procedure is based on the post-column reaction of amino acid groups with ninhydrin. Total amino acids were determined on freeze dried samples after initial oxidation with performic acid for cysteic acid and methionine sulphone, followed by acid hydrolysis using the method of Mason et al. (1980).

\section{Statistical analysis}

Repeated measures analysis of variance (procedure AREPMEASURES; Genstat release 8.2) was used for all statistical analysis because samples were taken from each cow at 30 , $60,90,120$ and $150 \mathrm{~min}$ after feeding. This procedure calculates an adjustment (Greenhouse-Geisser adjustment factor) to take account of the repeated measurements not being independent; these were $0.54,0.40$ and 0.26 for experiment 1 to 3 respectively. Repeated measures analysis of variance shows effects for treatment factors ('S source', 'cysteine level' and 'herbage' for experiments 1 to 3 respectively), 'time' and the 'treatment' $\times$ 'time' interaction. The effect of cysteine level (experiment 2) was partitioned into linear and quadratic effects. 'Experimental period' and 'cow' were used as blocking factors.

\section{Results}

In order to provide the clearest representation of the repeated measures analysis of variance, rumen head-space concentrations of hydrogen sulphide are presented graphically for each experiment (Figures 1 to 3 respectively). The corresponding s.e.d. and levels of significance are given in Table 3.

There were marked differences in both the relative concentrations and patterns of appearance of hydrogen sulphide in rumen head-space gas between the different $S$ sources (experiment 1). Cysteine led to a rapid and large

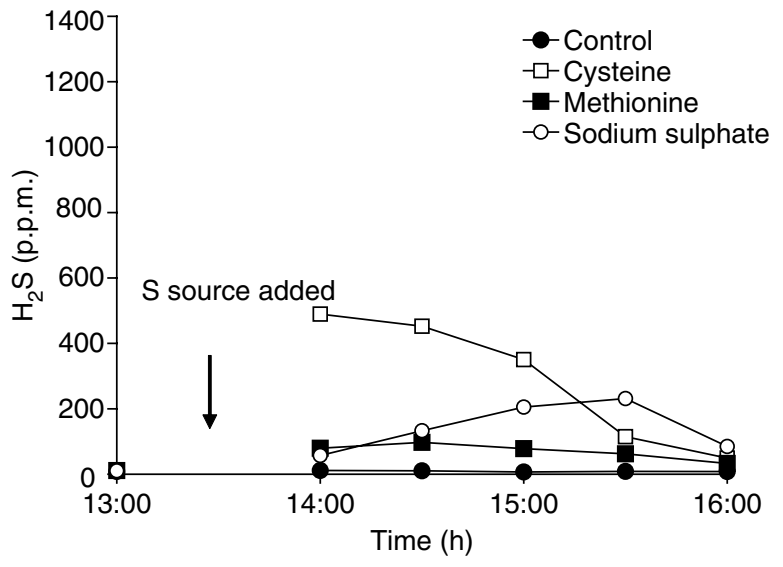

Figure 1 Effects of iso-S supplements of L-cysteine, L-methionine or sodium sulphate on the concentration of hydrogen sulphide in the rumen head-space gas of dairy cows (experiment 1) (four cows per treatment).

increase in hydrogen sulphide concentration, whilst concentrations were much less for the methionine addition. A slower increase in the concentration of hydrogen sulphide was evident for the addition of sodium sulphate, but the maximum value was less than half of that for cysteine.

The overall effect of increased cysteine supply, averaged across the five sampling points, was a linear increase (area under the curves for Figure 2). However, visual inspection of Figure 2, confirmed by the significant 'treatment' $x$ ' time' interaction, suggests a different temporal pattern with increasing level of cysteine addition. It appears that the rate at which rumen micro-organisms convert cysteine into hydrogen sulphide was saturated by additions of $8 \mathrm{~g}$ and that hydrogen sulphide concentration remained higher for longer with the highest addition of cysteine.

Perennial ryegrass feeding led to increased concentrations of hydrogen sulphide that were of the same order as was produced from cysteine in the previous study (Figure 3). Peak concentrations were achieved around $1.5 \mathrm{~h}$ after feeding, in contrast to the peak within 30 min for cysteine additions. The results of chemical analysis of the

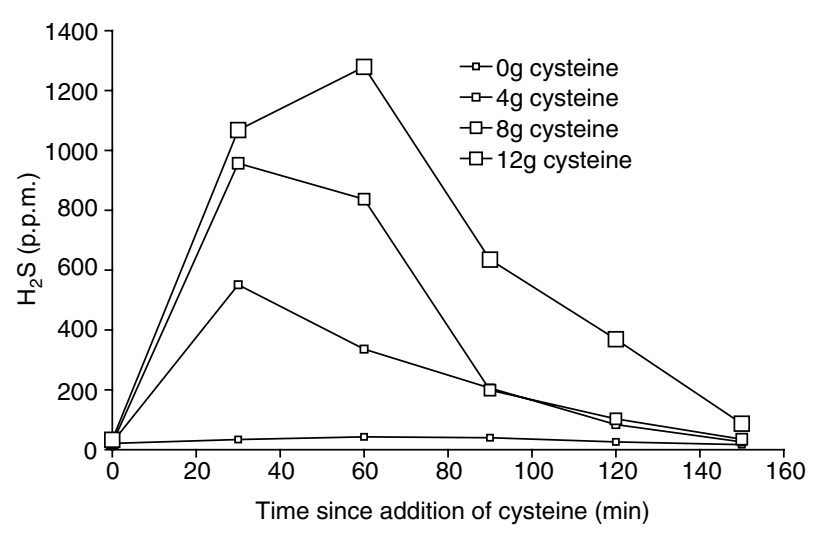

Figure 2 Effects of increasing quantities of supplementary L-cysteine on the concentration of hydrogen sulphide in the rumen head-space gas of dairy cows (experiment 2) (four cows per treatment). 


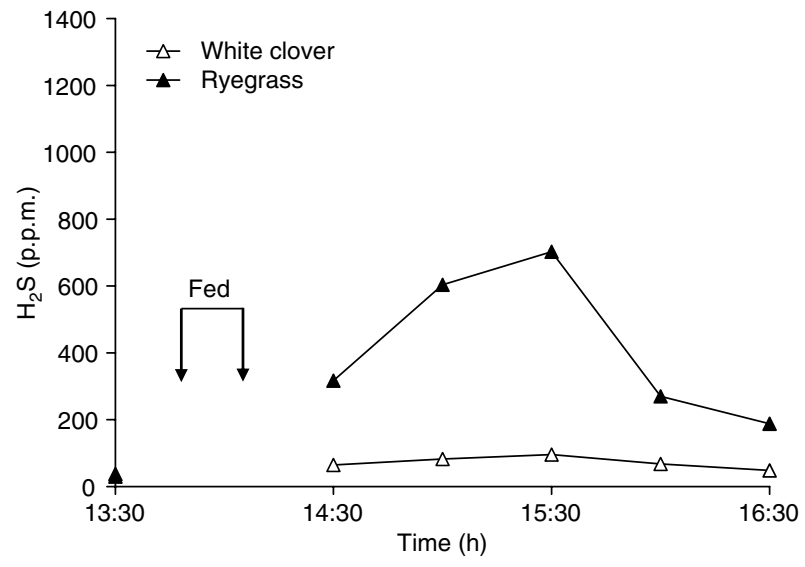

Figure 3 Effects of perennial ryegrass or white clover on the concentration of hydrogen sulphide in the rumen head-space gas of dairy cows (experiment 3 ) (four cows per treatment).

herbage offered to cows on recording days for experiment 3 is presented in Table 4. As expected, the white clover contained much higher levels of crude protein and sulphur amino acids than perennial ryegrass. Cystine content was proportionately 0.86 higher in white clover dry matter (DM) than perennial ryegrass DM, though the DM content of white clover was lower, so cystine intake was only 0.34 higher for cows offered white clover. Results for hydrogen sulphide concentrations with white clover were not as expected. Despite the much higher intake of cystine for white clover, there was almost no increase in hydrogen sulphide concentration in rumen head-space gas for cows fed white clover (Figure 3).

\section{Discussion}

In each of these experiments, rumen head-space gas concentrations of hydrogen sulphide declined from 500 to 1000 p.p.m. to close to zero within 3 to $4 \mathrm{~h}$ of feed being withdrawn, confirming previous observations (Dewhurst et al., 2001). One of the most striking features of that work was the rapid decline in concentrations within a few hours of food being removed.

The present study further demonstrated that very large changes in hydrogen sulphide can occur within $30 \mathrm{~min}$ of substrate (cysteine) becoming available. This is a much

Table 3 Repeated measures analysis of variance for effects of dietary treatments on the concentration of hydrogen sulphide (p.p.m.) in rumen head-space gas of dairy cows (values are presented in Figures 1 to 3 )

$$
\text { s.e.d. Significance }
$$

Experiment Treatment Time Interaction Treatment Time Interaction

\begin{tabular}{rrrrcccc}
\hline 1 & 28.7 & 25.6 & 57.6 & $* * *$ & $* *$ & $* * *$ \\
2 & 103.8 & 92.9 & 207.7 & $* * *($ LIN $)$ & $* * *$ & $* *($ LIN $)$ \\
3 & 56.3 & 35.6 & 79.6 & $* * *$ & $*$ & $*$ \\
\hline \hline
\end{tabular}

Table 4 Chemical composition of the herbage offered to cows during experiment 3

\begin{tabular}{lcc}
\hline \hline & $\begin{array}{c}\text { Perennial } \\
\text { ryegrass }\end{array}$ & White clover \\
\hline Dry matter (DM; g/kg as-fed) & 162 & 117 \\
Organic matter (g/kg DM) & 935 & 904 \\
Neutral-detergent fibre (g/kg DM) & 407 & 259 \\
Acid-detergent fibre (g/kg DM) & 225 & 228 \\
Crude protein (g/kg DM) & 129 & 258 \\
Ether extract (g/kg DM) & 21.7 & 24.5 \\
Water-soluble carbohydrates (g/kg DM) & 269 & 87 \\
Cystine (g/kg DM) & 1.14 & 2.13 \\
Methionine (g/kg DM) & 1.99 & 2.93 \\
\hline \hline
\end{tabular}

more dynamic situation than is evident with concentrations of other fermentation products, such as volatile fatty acids and ammonia, in rumen fluid. Indeed, the dynamics of hydrogen sulphide in rumen gas following the addition of cysteine appeared to be faster than has previously been observed in rumen fluid (Bird, 1972a). It is easy to speculate that such rapid changes in concentrations of such a toxic compound (Dougherty et al., 1962; Bird, 1972b) could influence aspects of animal performance, such as feeding behaviour and this is being investigated further.

Experiments 1 and 2 confirmed that cyst(e)ine is the dominant source of hydrogen sulphide in rumen gas. There was more modest production of hydrogen sulphide from the addition of sodium sulphate. The increase in concentration of hydrogen sulphide from sodium sulphate was less rapid than from cysteine suggesting some turnover before it can be released as hydrogen sulphide. These observations confirm earlier studies of hydrogen sulphide in rumen fluid (Bird and Hume, 1971; Bird, 1972a) that cyst(e)ine leads to much higher concentrations than methionine. This is probably a consequence of the slower rate of degradation of methionine (Lewis, 1955), as well as the production of other compounds (methanethiol and dimethyl sulphide) from methionine (Zikakis and Salsbury, 1969).

There were wide differences in the concentrations of hydrogen sulphide produced from similar quantities of amino acids across the different experiments. Whilst there was a linear increase in hydrogen sulphide concentrations (area under the curve for Figure 2) in response to increasing cysteine additions in experiment 2, the same addition of cysteine $(8 \mathrm{~g})$ led to different peak concentrations of hydrogen sulphide (490 and 957 p.p.m.) for experiments 1 and 2 respectively. Perennial ryegrass feeding led to intermediate peak concentrations (703 p.p.m.), whilst only $1.75 \mathrm{~g}$ of cyst(e)ine and $3.06 \mathrm{~g}$ of methionine were added. Comparisons between experiments must be regarded as weak, with a range of other cow and dietary factors affecting rumen function and so concentrations of hydrogen sulphide in rumen head-space gas. This is also reflected in considerable between-cow and between-day variation in concentrations of hydrogen sulphide with cows 
given the same diet (A.J.M. Fonseca, A.R.J. Cabrita and R.J. Dewhurst, unpublished observations).

Peak hydrogen sulphide concentration was $1.5 \mathrm{~h}$ after feeding perennial ryegrass, much later than for cysteine additions, reflecting the reduced availability of cystine within grass protein. Bird (1972a) noted that hydrogen sulphide production in rumen fluid should be a sensitive index of cyst(e)ine decomposition. However, given the variable response to similar additions of cysteine noted above, we do not anticipate that hydrogen sulphide concentrations in rumen head-space gas would provide a sensitive assay for protein degradation.

The weak relationship between protein degradation and hydrogen sulphide concentrations is further illustrated in the results for white clover. White clover led to very low concentrations of hydrogen sulphide in rumen head-space gas despite the higher concentration of cystine in white clover in comparison with perennial ryegrass. This is in agreement with Moate et al. (1997), who were unable to detect hydrogen sulphide in the rumen gas of cows grazing white clover/ perennial ryegrass pasture. Further consideration of this observation reveals that cyanogenesis in white clover might provide an explanation. Micro-organisms can detoxify hydrogen cyanide by combining it with hydrogen sulphide to produce thiocyanate (Onwuka et al., 1992).

There are a number of implications of the observations about white clover and this effect is worthy of further investigation. The cyanide detoxification mechanism might explain why excessive protein content is not regarded as a problem with white clover, whilst similarly high protein contents in grasses that have received high levels of nitrogen fertiliser lead to reductions in voluntary intake in some (e.g. Ferri et al., 2004) but not all (Demarquilly, 1970) studies. Indeed, we can speculate that these effects could be involved in the carefully regulated diurnal preferences of ruminants for ryegrass and white clover (Rutter et al., 2004). The variability of responses in rumen head-space hydrogen sulphide concentrations between experiments was a feature of this work. Possible effects on intake and performance mean that further studies should seek to understand animal and diet factors that contribute to this variation.

\section{Acknowledgements}

The financial support of Department for the Environment, Food and Rural Affairs (UK) is gratefully acknowledged. The authors acknowledge the skilled technical assistance of
P. Connelly, L.J. Harris and amino acid analysis conducted by P. Rees-Stevens of the IGER analytical chemistry laboratory.

\section{References}

Bird PR 1972a. Sulphur metabolism and excretion studies in ruminants. V. Ruminal desulphuration of methionine and cyst(e)ine. Australian Journal of Biological Science 25, 185-193.

Bird PR 1972b. Sulphur metabolism and excretion studies in ruminants. $X$. Sulphide toxicity in sheep. Australian Journal of Biological Science 25, 1087-1098.

Bird PR and Hume ID 1971. Sulphur metabolism and excretion studies in ruminants. IV. Cystine and sulphate effects upon the flow of sulphur from the rumen and upon sulphur excretion by sheep. Australian Journal of Agricultural Research 22, 443-452.

Broderick GA and Albrecht KA 1997. Ruminal in vitro degradation of protein in tannin-free and tannin-containing forage legume species. Crop Science 37, 1884-1891.

Demarquilly C 1970. Influence de la fertilisation azotée sur la valeur alimentaire des fourrages verts. Annales de Zootechnie 19, 423-437.

Dewhurst RJ, Evans RT, Mottram TT, Španěl P and Smith D 2001. Assessment of rumen processes by selected-ion-flow-tube mass spectrometric analysis of rumen gases. Journal of Dairy Science 84, 1438-1444.

Dewhurst RJ, Moorby JM, Dhanoa MS, Evans RT and Fisher WJ 2000. Effects of altering energy and protein supply to dairy cows during the dry period. 1. Intake, body condition and milk production. Journal of Dairy Science 83, 1782-1794.

Dougherty RW, Stewart WE, Nold MM, Lindahl IL, Mullenax $\mathrm{CH}$ and Leek BF 1962. Pulmonary absorption of eructated gas in ruminants. American Journal of Veterinary Research 23, 205-212.

Ferri CM, Stritzler NP and Pagella JH 2004. Nitrogen fertilization on rye pasture: effect on forage chemical composition, voluntary intake, digestibility and rumen degradation. Journal of Agronomy and Crop Science 190, 347-354.

Gould DH, Cummings BA and Hamar DW 1997. In vivo indicators of pathologic ruminal sulphide production in steers with diet-induced polioencephalomalacia. Journal of Veterinary Diagnostics and Investigation 9, 72-76.

Havlin JL, Tisdale SL, Nelson W and Beaton J 1999. Soil fertility and fertilisers: an introduction to nutrient management, sixth edition. Prentice-Hall, Upper Saddle River, NJ, USA.

Lewis D 1955. Amino acid metabolism in the rumen of the sheep. British Journal of Nutrition 9, 215-230.

Mason VS, Bech-Andersen S and Rudemo M 1980. Hydrolysate preparation for amino acid determination in feed constituents. 8. Studies of oxidation conditions for streamlined procedures. Zeitschrift für Tierphysiologie Tierernährung und Futtermittelkunde 43, 146-164.

Moate PJ, Clarke T, Davis LH and Laby RH 1997. Rumen gases and bloat in grazing dairy cows. Journal of Agricultural Science, Cambridge 129, 459-469.

Onwuka CFI, Akinsoyinu AO and Tewe 00 1992. Role of sulphur in cyanide detoxification in ruminants. Small Ruminant Research 8, 277-284.

Rutter SM, Orr RJ, Yarrow NH and Champion RA 2004. Dietary preference of dairy cows grazing ryegrass and white clover. Journal of Dairy Science 87, $1317-1324$

Zikakis JP and Salsbury RL 1969. Metabolism of sulphur amino acids by rumen microorganisms. Journal of Dairy Science 52, 2014-2019. 